\title{
IMPLEMENTASI SISTEM PERSEDIAAN DENGAN METODE GRAFIK DAN PENERAPAN LAST IN FIRST OUT PADA HASANAH COLLECTION
}

\author{
Irzal Arief Wisky \\ Universitas Putra Indonesia YPTK Padang \\ E-mail : irzal_ariefwisky@upiyptk.ac.id
}

\begin{abstract}
The purpose of this research is to produce applications that can provide information about inventory, because this is very important in the world of organizations engaged in marketing and selling goods. So from that the authors conducted research on hasanah collection, implementation is applied to determine improving the ability of the inventory system in scheduling and selling processes. For this reason, a computerized system was built so as to minimize the calculation error to determine the amount of ending inventory in hasanah collection.
\end{abstract}

Keywords : Inventory, Marketing, Implementation, scheduling

\begin{abstract}
Abstrak
Tujuan dari penelitian ini adalah untuk menghasikan aplikasi yang mampu memberikan informasi mengenai Persediaan barang, karena inilah yang sangat penting dalam dunia organisasi yang bergerak dibidang pemasaran dan penjualan barang. Maka dari pada itu penulis melakukan penelitian pada hasanah collection, implementasi diterapkan untuk menentukan meningkatkan kemampuan sistem persediaan barang dalam melakukan proses penjadwalan dan penjualan. Untuk itu dibangun sebuah sistem yang terkomputerisasi sehingga dapat meminimalkan terjadinya kesalahan perhitungan untuk menentukan jumlah persediaan akhir pada hasanah collection.
\end{abstract}

Kata Kunci : Persediaan, Pemasaran, Implementasi, penjadwalan

\section{Pendahuluan}

\section{Latar Belakang}

Sistem pencatatan transaksi penjualan yang ada di hasanah collection pada saat ini masih belum maksimal, seiring perkembangan teknologi informasi dunia usaha harus mampu bersaing dan berkembang dengan memanfaatkan aplikasi, seperti update stok barang dan transaksi keluar masuk barang dicatat dan di-update. Dengan demikian perhitungan jumlah barang yang terjual ataupun yang belum terjual dapat terlihat dengan jelas. Hal tersebut memungkinkan terjadinya peningkatan pelayanan dan transaksi.

Dalam peningkatan kualitas sistem kea rah yang lebih baik diperlukan solusi yang tepat, yaitu menerapkan aplikasi sistem informasi dalam penyebarluasan produk-produk yang ada. Metode yang digunakan ialah Last In First Out (LIFO Method). Metode ini mengasumsikan bahwa nilai barang yang terjual atau terpakai dihitung berdasarkan harga pembelian barang yang terakhir masuk dan nilai akhir dihitung berdasarkan harga pembelian yang terdahulu masuk. ${ }^{[1]}$.

Untuk mendukung jalannya sistem, dibutuhkan juga graphic method (metode grafik ) yang bertujuan untuk melihat total transaksi yang terjadi setiap bulan untuk memudahkan karyawan dalam melaporkan data transaksi penjualan. Dengan menggunakan metode grafik, pemilik dapat melihat visual atau desain yang merepresentasikandata yang dibuat dengan menggunakan bantuan hardware atau software khusus pada komputer.

Metode grafik yang digunakan pada Hasanah Collection akan berkenaan dengan grafik penjualan dan grafik pembelian. Pada grafik penjualan, dapat dilihat perbandingan penjualan sehingga pemilik 
dapat mengetahui tingkat penjualan suatu barang. Sementara itu, melalui grafik pembelian, dapat dilihat data pembelian kepada supplier sehingga dapat diketahui tingkat pembelian suatu barang.

Penelitian ini bertujuan untuk merancang sistem infromasi pada Hasanah Collection untuk mempermudah pengguna dalam pengolahan data, pembuatan laporan, grafik penjualan dan mempermudah dalam pencarian data.

\section{Tujuan Penelitian}

Adapun tujuan dari penelitian ini adalah (1) Mengimplementasikan suatu sistem informasi yang akan digunakan untuk memberikan informasi yang tepat dan akurat. (2)Penyajian informasi Persediaan yang lebih baik sehingga memudahkan proses transaksi dan penyusunan laporan.

\section{Metode Penelitian}

Agar penelitian ini mendapat hasil yang diharapkan, maka diperlukan kerangka kerja penelitian, dimana kerangka penelitian yang dilakukan digambarkan seperti Gambar 1.

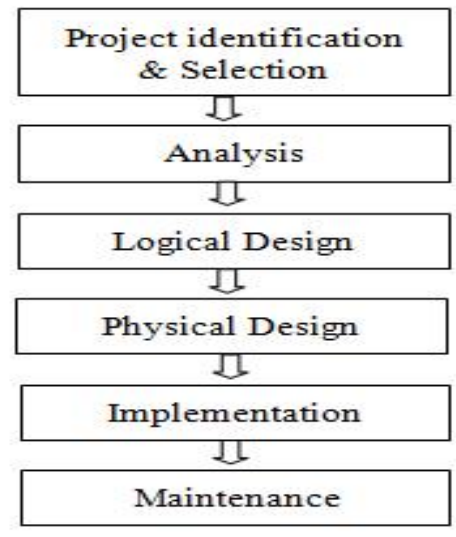

Gambar 1 Kerangka Penelitian

\section{Project Identification \& Selection}

Yakni Yang berhubungan dengan aktifitas perencanaan Sistem, yaitu menentukan prioritas sistem dan proyek, arsitektur dari data, jaringan, hardware, dan manajemen dari sistem informasi.

\section{Analysis, menghasilkan}

Penjabaran mengenai sistem yang ada termasuk masalah atau peluang yang ada yang direkomendasi untuk diperbaik/diatasi, ditingkatkan, atau mengganti sistem yang ada, uraian mengenai sistem pilihan dan sistem perundangan/pertimbangan untuk sistem yang terpilih, kesulitan yang ditemui dan menemukan berbagai solusi untuk mengatasi berbagai hambatan yang ditemukan.

\section{Logical Design}

Berhubungan dengan fungsi-fungsi, spesifikasi terperinci dari semua element sistem (data, proses, input, output)

\section{Physical design}

Untuk menghasilkan aplikasi Lebih bersifat teknis, spesifikasi terperinci dari semua element sistem (program, file-file, sistem software, dll), rencana untuk teknologi baru.

\section{Implementation}

Yakni menghasilkan : Proses sistem, dokumentasi, prosedur pelatihan, dan support /dukungan yang dapat diberikan. 


\section{Maintenance}

Yakni dapat menghasilkan : Software versi terbaru atau dengan pembaruan untuk dokumentasi, pelatihan, support/dukungan.

\section{Hasil dan Pembahasan}

Pada bagian ini akan disajikan hasil penelitian yang merupakan salah satu tahap dalam daur hidup pengembangan sistem, dimana tahap ini merupakan tahap agar sistem informasi siap untuk digunakan. Dalam tahap ini berlangsung beberapa aktifitas secara berurutan yakni mulai dari menerapkan rencana implementasi, melakukan kegiatan implementasi, dan tindak lanjut implementasi.

\section{Aliran Sistem Informasi}

Yakni menggambarkan alur kerja sistem, sehingga setiap proses perpindahan file yang terjadi tergambarkan dengan detail dan rinci, dapat dilihat pada Gambar 2 berikut :

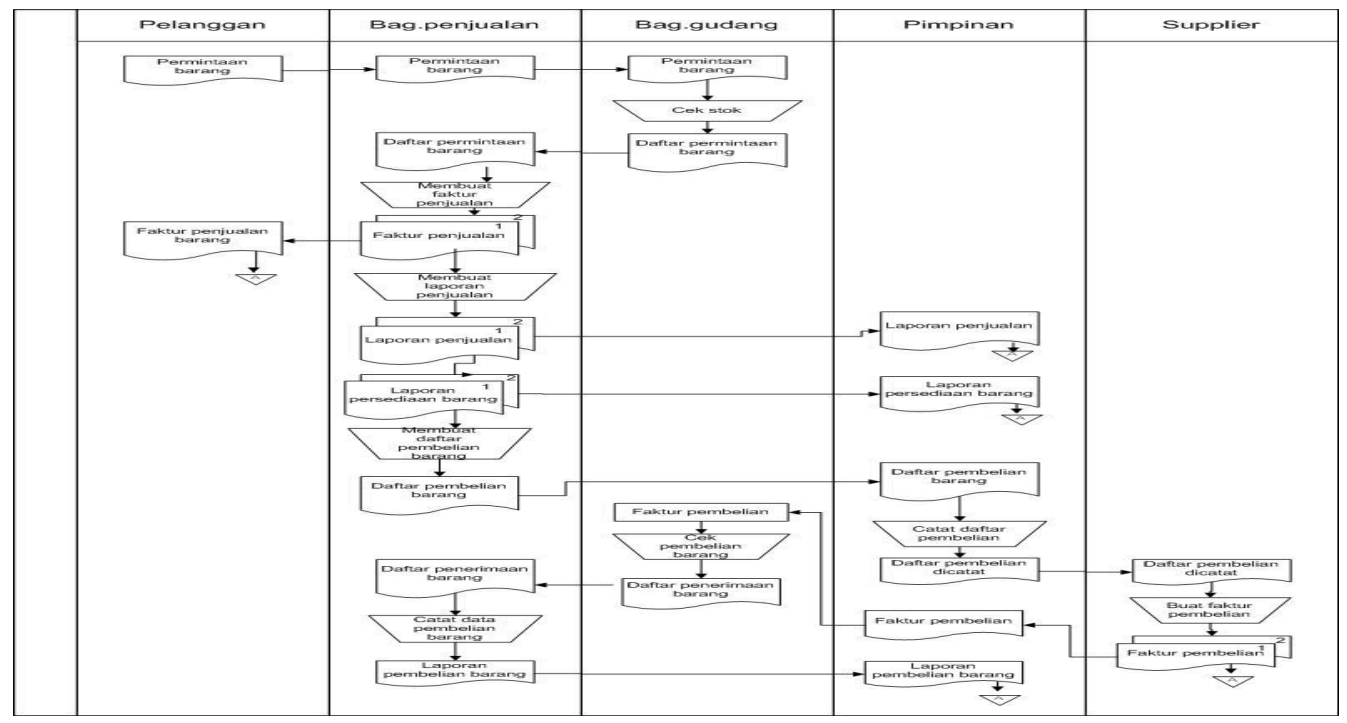

Gambar 2 Aliran Sistem Informaasi

\section{Context Diagram}

Context Diagram adalah gambaran umum tentang suatu sistem yang terdapat dalam suatu organisasi yang memperlihatkan batasan (boundary) sistem, seperti Gambar 3 berikut :

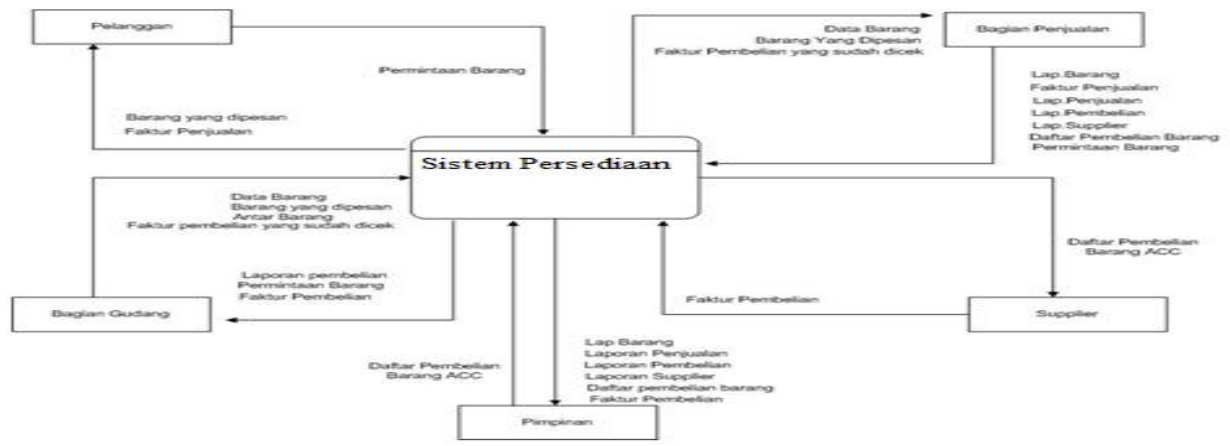


Supaya implementasi berjalan dengan baik dan sesuai dengan yang diharapkan, maka suatu rencana implementasi perlu dibuat terlebih dahulu. Rencana implementasi ini dimaksudkan untuk mengatur biaya serta waktu yang dibutuhkan selama tahap implementasi.

\section{Login Sistem}

Layout ini merupakan interface yang akan digunakan oleh pengguna aplikasi. Terdiri dari username dan password. Tampilan menu dapat dilihat pada Gambar 4 berikut ini:

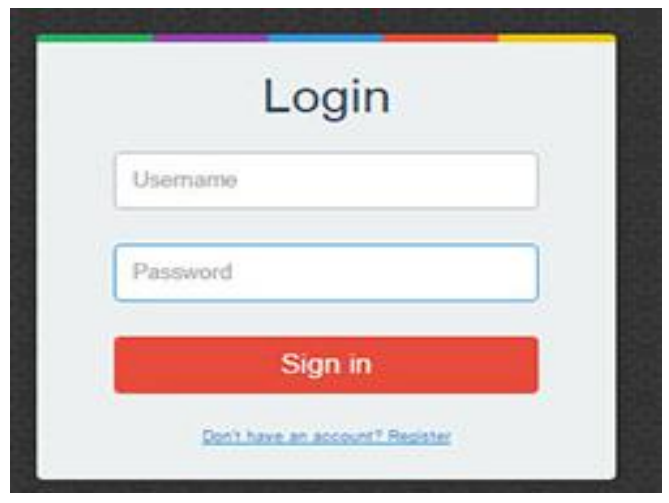

Gambar 4 Login sistem

\section{Menu Utama}

Layout ini merupakan interface utama yang akan digunakan oleh pengguna aplikasi. Terdiri dari Home, jilbab dewasa, baju wanita, jilbab anak, aksesoris. Tampilan menu utama dapat dilihat pada Gambar 5 berikut ini:

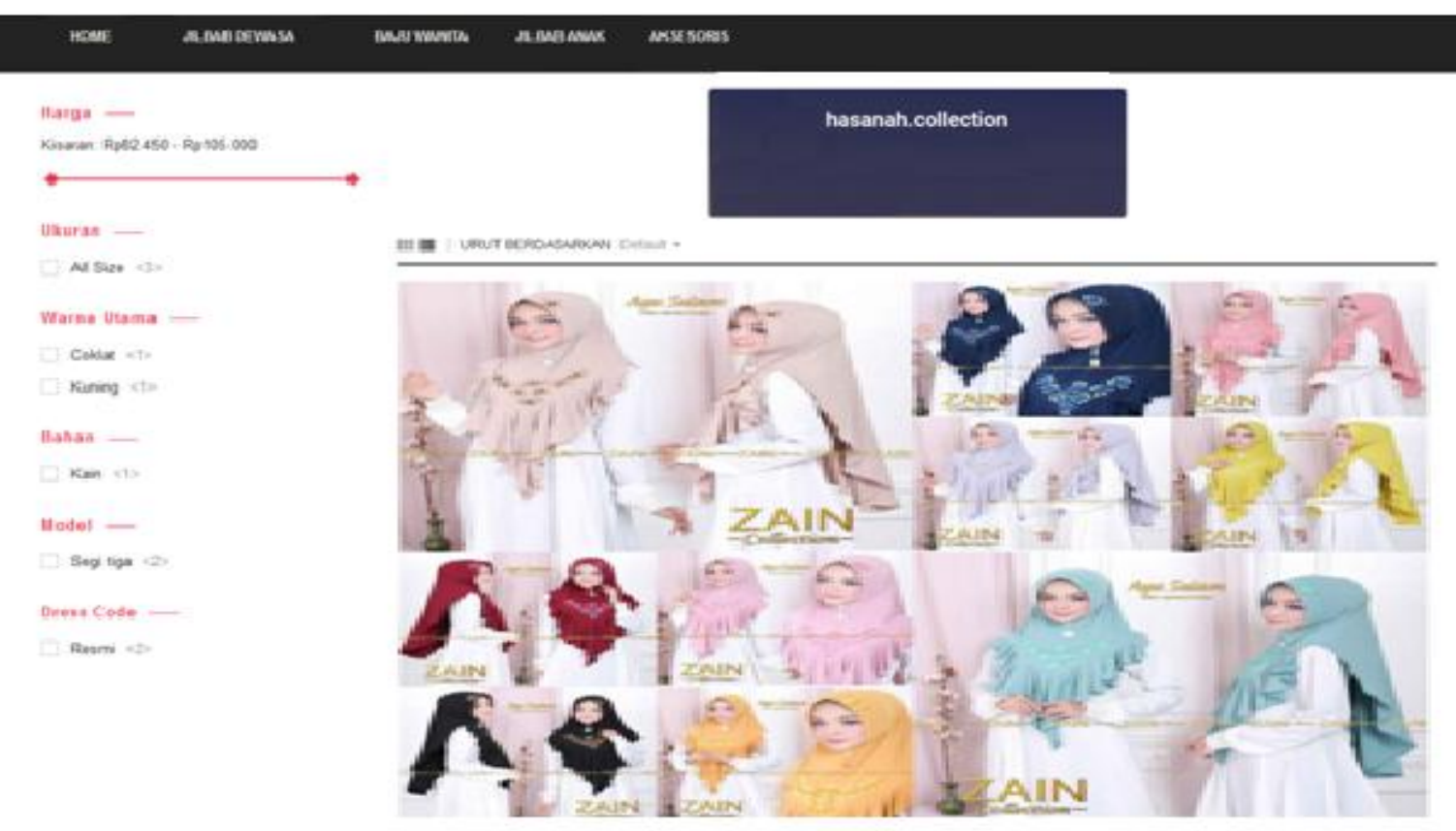

Gambar 5 Home Utama 


\section{Menu Tampilan Grafik}

Tampilan ini merupakan interface yang akan digunakan untuk menampilkan grafik persebaran data. Terdiri dari data : jilbab dewasa, aksesoris, jilbab anak, baju wanita. Tampilan grafik dapat dilihat pada Gambar 6 berikut ini:

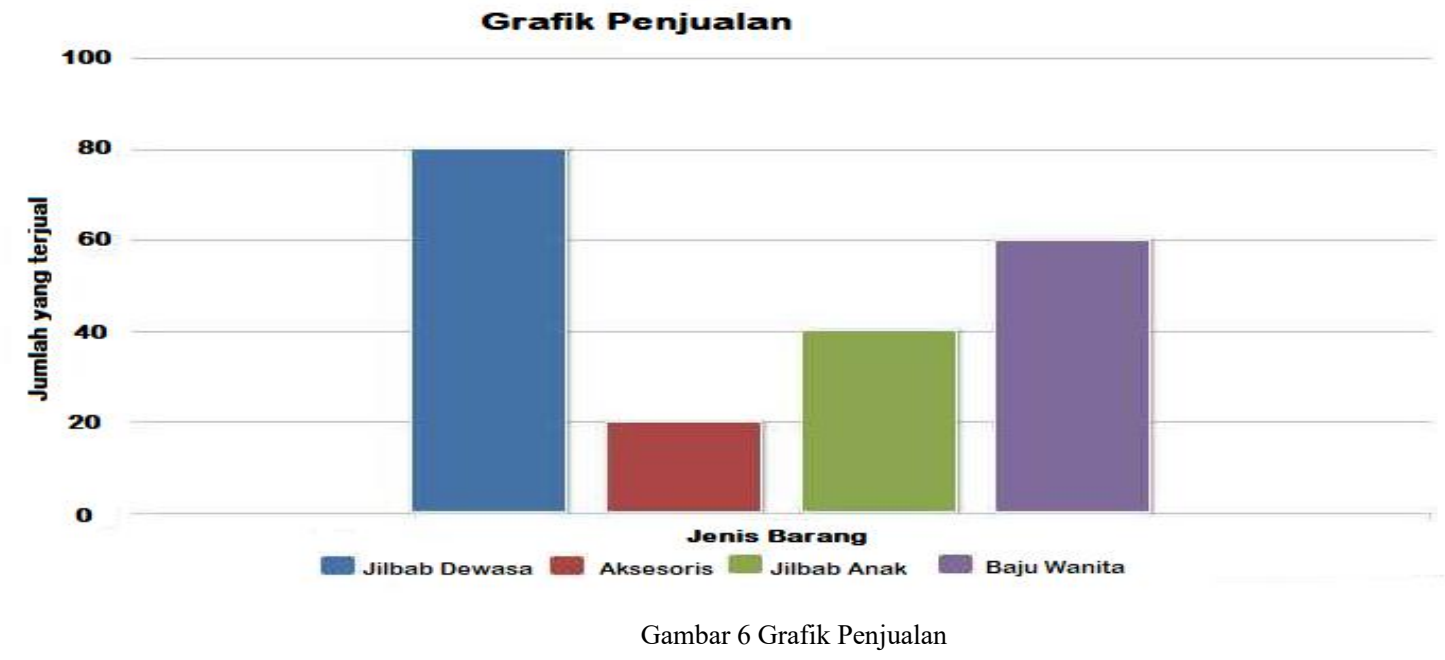

\section{Kesimpulan}

Berdasarkan dari penelitian yang telah penulis lakukan pada hasanah collection maka dapat diambil kesimpulan sebagai berikut: (1) Dengan diterapkannya sistem informasi persediaan yang komputerisasi akan mengatasi masalah yang dihadapi. (2) Dengan adanya sistem informasi ini lebih efesiensi dalam pengolahan data persediaan barang serta pembuatan laporan lebih jelas dan akurat. 


\section{Daftar Rujukan}

[1] Apridian, Setiawan. 2014. Sistem Informasi Persediaan Bahan Bakar Minyak Pada SPBU. Salatiga

[2] Hidayatullah, Priyanto.2015. Visual Basic.NET Membuat Aplikasi Database dan Program Kreatif. Informatika, Bandung.

[3] Pratama, I Putu Agus Eka. 2014. Sistem Informasi dan Implementasinya. Informatika, Bandung.

[4] Agus Mulyanto. 2009. Sistem Informasi Konsep dan Aplikasi. Pustaka Pelajar. Yogyakarta

[5] Sutarman. 2012. Pengantar Teknologi Informasi. Jakarta: PT. Bumi Aksara.

[6] Sari,Dian Indah. “Analisis Perhitungan Persediaan dengan Metode FIFO dan Average Pada PT.Harapan”. 2014. Vol.XVI No.1, Maret 2018

[7] Andono,Pulung Nurtianto dan T.Sutojo. 2016. Grafika Komputer. Penerbit : Andi, (Anggota IKAPI)

[8] Sutabri, Tata. 2012. Konsep Sistem Informasi. Andi, Yogyakarta.

[9] M.Shalahuddin, Rosa A.S.2013. Rekayasa Perangkat Lunak. Informatika, Bandung.

[10] Yakub.2012.Pengantar Sistem Informasi : Graha Ilmu.

[11] Afyenni, Rita.2014. "Perancangan Data Flow Diagram untuk Sistem Informasi Sekolah (Studi Kasus pada SMA Pembangunan Laboratorium UNP)”. Jurnal TEKNOIF, Vol. 2, No. 1, April 2014, ISSN : 2338-2724.

[12] Saputra, Rusli. 2015. "Desain Sistem Informasi Order Photo Pada Creative Studio Photo Dengan Menggunakan Bahasa Pemrograman Visual Basic.Net 2010”. Jurnal Momentum Vol.17 No.2, Agustus 2015, ISSN : 1693-752X.

[13] Purnamayudhi, Onny dan Eko Budi Satoto.2014. "Aplikasi Sistem Informasi Penjualan Apotek”. Jurnal Teknik Industri, ISSN : 1411-6340. 